\title{
CARA MENSINTESISKAN LITERATURE DALAM PENELITIAN
}

Titik Rahayu $^{1}$, Syafrimen Syafril ${ }^{2}$

${ }^{1}$ Fakulty of Education, Universiti Kebangsaan Malaysia, 43600 UKM Bangi, Selangor, Malaysia. Email: p91583@siswa.ukm.edu.my

${ }^{2}$ Universitas Negeri Islam Raden Intan Lampung, J1. Letnan Kolonel H. Endro Suratmin, Sukarame, Kota Bandar Lampung, Lampung 35131, Indonesia. Email: syafrimen@radenintan.ac.id 


\section{CARA MENSINTESISKAN LITERATURE UNTUK PENELITIAN}

Titik Rahayu $^{1}$, Syafrimen Syafrii ${ }^{2}$

${ }^{1}$ Fakulty of Education, Universiti Kebangsaan Malaysia, 43600 UKM Bangi, Selangor, Malaysia. Email: p91583@ siswa.ukm.edu.my

${ }^{2}$ Universitas Negeri Islam Raden Intan Lampung, Jl. Letnan Kolonel H. Endro Suratmin, Sukarame, Kota Bandar Lampung, Lampung 35131, Indonesia. Email: syafrimen@radenintan.ac.id

JUDUL PENELITIAN:

KEYAKINAN DIRI TERHADAP KEMAHIRAN PEMIKIRAN KOMPUTASIONAL DALAM KALANGAN CALON GURU SAINS

\section{A. KEMAHIRAN PEMIKIRAN KOMPUTASIONAL (COMPUTER THINGKING)}

\begin{tabular}{|l|l|}
\hline Wing (2006) & $\begin{array}{l}\text { Pemikiran pengiraan melibatkan "menyelesaikan masalah berbentuk sistem, dan memahami } \\
\text { tingkah laku manusia, dengan menggambarkan pada konsep-konsep asas sains komputer". }\end{array}$ \\
\hline $\begin{array}{l}\text { Astrachan, Hambrusch, } \\
\text { Peckham, \& Settle, 2009 }\end{array}$ & $\begin{array}{l}\text { Pemikiran komputasi dianggap sebagai set alat penyelesaian masalah yang melampaui } \\
\text { teknologi maklumat (IT), kelancaran untuk memohon prinsip pengkomputeran seperti } \\
\text { abstraksi, penguraian, generalisasi, pengiktirafan corak, dan pemikiran algoritma dan selari. }\end{array}$ \\
\hline Cuny et al. 2010 & $\begin{array}{l}\text { Proses pemikiran yang terlibat dalam merumuskan masalah dan penyelesaian supaya } \\
\text { penyelesaian diwakili dalam bentuk yang boleh menjadi keberkesanan-tively dijalankan oleh } \\
\text { ejen memproses maklumat. }\end{array}$ \\
\hline $\begin{array}{l}\text { Computer Science Teachers } \\
\text { Association (CSTA) and the } \\
\text { International Society for } \\
\text { Technology in Education } \\
\text { (ISTE) (2011) }\end{array}$ & $\begin{array}{l}\text { Pendekatan untuk menyelesaikan masalah dengan cara yang boleh dilaksanakan dengan } \\
\text { komputer. Menggunakan satu set konsep, seperti abstraksi, rekursi, dan lelaran, untuk } \\
\text { memproses dan menganalisis data, serta untuk membuat artifak sebenar dan maya. }\end{array}$ \\
\hline
\end{tabular}




\begin{tabular}{|c|c|}
\hline $\begin{array}{l}\text { (Barr \& Stephenson, } \\
2011, \text { ms. 51) }\end{array}$ & $\begin{array}{l}\text { Metodologi penyelesaian masalah yang boleh automatik dan dipindahkan serta digunakan } \\
\text { merentasi subjek. }\end{array}$ \\
\hline Swaid 2015 & $\begin{array}{l}\text { Melibatkan penyelesaian masalah, bentuk sistem, dan memahami tingkah laku manusia, } \\
\text { dengan melukis pada konsep-konsep asas kepada Sains Komputer dan juga Pemikiran } \\
\text { Komputasional termasuk pelbagai alat pemikiran yang mencerminkan keluasan bidang Sains } \\
\text { Komputer. }\end{array}$ \\
\hline Aho (2012) & $\begin{array}{l}\text { Pemikiran komputasional sebagai proses pemikiran yang melibatkan perumusan masalah } \\
\text { sehingga pelajar boleh menyelesaikan masalah melalui langkah-langkah pengiraan dan } \\
\text { algoritma. }\end{array}$ \\
\hline Selby dan Woollard (2013) & $\begin{array}{l}\text { Proses kognitif atau mental, manusia, bukan mesin, penyelesaian masalah dalam erti kata yang } \\
\text { luas, dan melibatkan kebolehan seperti: Abstraksi (penakulaan), iaitu menyembunyikan } \\
\text { kerumitan realiti yang wujud; penguraian, membahagikan tugas atau masalah kedalam } \\
\text { bahagian mudah supaya lebih mudah menyelesaikan masalah yang rumit; Algoritma, } \\
\text { menentukan tugas sebagai satu set langkah demi langkah dengan memiliki arahan yang } \\
\text { mudah; Penilaian, menilai kelebihan dan batasan penyelesaian; serta Pengumuman, iaitu } \\
\text { keadaan khusus ke lebih umum. }\end{array}$ \\
\hline Selby, 2015 & $\begin{array}{l}\text { Pemikiran komputasi boleh dianggap sebagai set alat penyelesaian masalah yang melampaui } \\
\text { teknologi maklumat (IT) kelancaran untuk memohon prinsip pengkomputeran seperti } \\
\text { abstraksi, penguraian, generalisasi, pengiktirafan corak, dan pemikiran algoritma dan selari. }\end{array}$ \\
\hline Csizmadia, A. et al. (2015) & $\begin{array}{l}\text { Pemikiran Komputasional merupakan proses penyelesaian masalah yang memerlukan usaha } \\
\text { memecahkan sesuatu masalah kepada komponen yang lebih kecil (Decompose), cuba } \\
\text { mengekstrak idea ataupun maklumat yang penting dan relevan (Abstraction), mengenali corak } \\
\text { (Pattern) yang membolehkan perancangan penyelesaian yang tepat bagi mengelakkan ulangan } \\
\text { dan tindakan yang kurang releven supaya meningkatkan keberkesanan proses penyelesaian } \\
\text { masalah tersebut. Individu perlu menggunakan pemikiran logikal (Logical Reasoning) bagi } \\
\text { mengenalpasti maklumat yang penting dan mengaturkan langkah penyelesaian mengikut } \\
\text { turutan yang logikal (Algorithm), menilai pemilihan dan keputusan yang telah dilakukan bagi } \\
\text { menguji kesahihan dan keboleh laksanaan prosedur tersebut (Evaluation). }\end{array}$ \\
\hline
\end{tabular}




\begin{tabular}{|l|l|}
\hline $\begin{array}{l}\text { Meng-Chuan Tsai, Chia-Wen } \\
\text { Tsai, 2017) }\end{array}$ & $\begin{array}{l}\text { Co mputational thinking involves solving problems, designing systems, and understanding } \\
\text { human behavior, by drawing on the concepts fundamental to computer science }\end{array}$ \\
$\begin{array}{l}\text { Meng-Chuan Tsai, Chia-Wen } \\
\text { Tsai.(2017) "Applying online } \\
\text { externally-facilitated } \\
\text { regulated learning and } \\
\text { computational } \\
\text { thinking to improve students' } \\
\text { learning," Universal Access } \\
\text { in the Information Society, } \\
\text { pp.1-10. }\end{array}$ & \\
\hline
\end{tabular}

\section{Cara Mensintesiskan Berbagai Pandangan di Atas:}

Untuk melakukan sintesis secara manual terhadap berbagai pandangan tentang pemikiran komputasional seperti dipaparkan di atas, kita perlu membaca, memahami dan menganalisis dengan baik maksud yang disampaikan oleh penulis dalam konsep yang mereka kemukakan. Untuk memudahkan melakukan itu, bisa dilakukan dengan mengambil poin-poin atau kata kunci-kata kunci yang digunakan oleh penulis dalam mengemukakan konsep mereka. Seterusnya setiap konsep yang sama atau memiliki makna yang lebih kurang sama, boleh kita sintesiskan menjadi satu ide, sehingga dalam melaporkan kita tidak perlu berulang. Dalam melakukan penelitian ilmiyah, sebenarnya yang kita kutip itu adalah "ide" bukan mengulang penulisan semua yang ditulis oleh penulis sebelum kita. Begitulah seterusnya proses yang perlu kita lakukan dalam mengambil berbagai ide orang lain untuk dimasukan ke dalam penulisan kita. Pekerjaan mensintesiskan berbagai pandangan orang lain ini akan lebih mudah dilakukan dengan menggunakan software NVIVO.

\section{Contoh Hasil Sintesiskan dari Berbagai Pandangan di Atas:}

Secara keseluruhan para pakar bersetuju bahawa kemahiran pemikiran komputasional adalah satu kemahiran sebagai alat penyelesaian masalah dalam kehidupan manusia (Aho 2012; Astrachan, Hambrusch, Peckham, \& Settle 2009; Barr \& Stephenson 2011; Computer Science Teachers Association (CSTA) and the International Society for Technology in Education (ISTE) 2011; Csizmadia, A. et al. 
2015; Cuny et al. 2010; Meng-Chuan Tsai, Chia-Wen Tsai 2017; Selby dan Woollard 2013; Selby 2015; Swaid 2015; Wing 2006). Meskipun demikian, terdapat beberapa perbezaan pendapat daripada aspek-aspek yang berkaitan dengan definisi kemahiran pemikiran komputasional yang dipaparkan pakar-pakar tersebut.

Meng-Chuan Tsai, Chia-Wen Tsai (2017) dan Wing (2006) memiliki definisi yang sama terhadap kemahiran pemikiran komputasional, iaitu pemikiran komputasional yang melibatkan menyelesaikan masalah, merancang sistem, dan memahami tingkah laku manusia, dengan menarik konsep-konsep asas kepada sains komputer. Berdasarkan definisi pandangan Meng-Chuan Tsai, ChiaWen Tsai (2017) dan Wing (2006) tersebut kemahiran pemikiran komputasional tidak hanya melibatkan teknologi perkomputeran dalam menyelesaikan masalah, namun dapat dilakukan melalui tanpa bantuan teknologi perkomputeran seperti tingkah laku manuasia. Contohnya, dalam menggunakan teknik leraian boleh digunakan untuk menyelesaikan masalah dengan memisahkan beberapa jenis bahan kepada beberapa bahagian yang lebih kecil dan ringkas (anonim 2018).

Dalam perspektif lain, Astrachan, Hambrusch, Peckham, dan Settle (2009) dan Selby (2015) mendefinisikan kemahiran pemikiran komputasional yang berfokus terhadap set alat penyelesaian masalah yang melampaui teknologi maklumat (IT) melalui prinsip perkomputeran seperti abstraksi, penguraian, generalisasi, pengiktirafan corak, dan pemikiran algoritma dan parallelism.

\section{A.1 Kepentingan ICT Untuk Masa Depan}

\begin{tabular}{|l|l|}
\hline (Gareis et al., 2014) & $\begin{array}{l}\text { Kemahiran yang sama kekurangan dan impak ekonomi seterusnya telah diramalkan oleh } \\
\text { orang Eropah. Suruhanjaya, mendorong panggilan untuk integrasi kemahiran digital ke } \\
\text { peringkat awal peringkat pendidikan sekolah. }\end{array}$ \\
\hline $\begin{array}{l}\text { The Chartered Institute for } \\
\text { IT, 2010) }\end{array}$ & $\begin{array}{l}\text { Membekalkan kanak-kanak dengan kemahiran pemikiran komputasi asas yang akan } \\
\text { menyokong penyertaan dalam kami masyarakat digital dan ekonomi adalah penting untuk } \\
\text { kemakmuran masa depan. }\end{array}$ \\
\hline $\begin{array}{l}\text { Yadav, A.,Mayfield, C., Zhou, N., } \\
\text { Hambrusch, S., and Korb, J. T. 2014. }\end{array}$ & $\begin{array}{l}\text { pemikiran komputasional mempunyai potensi untuk memajukan kemahiran dan kebolehan } \\
\text { penyelesaian masalah pelajar dengan ketara kerana mereka mula berfikir dengan cara yang } \\
\text { baru. }\end{array}$ \\
\hline
\end{tabular}

Comment [M1]: Anonim. 2018. Asas Sains Komputer Tingkatan 1. Online (13/10/2018: 4.08 PM).

https://theonlybasicsciencecomputer.blogspot.com/p/1_9.html 


\begin{tabular}{|c|c|}
\hline $\begin{array}{l}\text { (Selby, 2015). } \\
\text { Selby, C. C. (2015). Relationships: } \\
\text { computational thinking, pedagogy of } \\
\text { programming, and } \\
\text { bloom's taxonomy. In Proceedings of } \\
\text { the Workshop in Primary and } \\
\text { Secondary Computing } \\
\text { Education on ZZZ (pp. 80-87). New } \\
\text { York: ACM. }\end{array}$ & $\begin{array}{l}\text { Baru-baru ini, pemikiran komputasi }(\mathrm{CT}) \text { telah dianjurkan sebagai abad kedua puluh satu } \\
\text { kemahiran yang perlu dimiliki pelajar untuk membangunkan kemahiran menyelesaikan } \\
\text { masalah menggunakan prinsip dari sains komputer. }\end{array}$ \\
\hline $\begin{array}{l}\text { Lye, S. Y., \& Koh, J. H. L. (2014). } \\
\text { Review on teaching and learning of } \\
\text { computational thinking } \\
\text { through programming: What is next } \\
\text { for K-12? Computers in Human } \\
\text { Behavior, 41, 51-61. }\end{array}$ & $\begin{array}{l}\text { Untuk pemikiran komputasi untuk menjadi sebahagian daripada kurikulum K-12, ada } \\
\text { keperluan kritikal untuk menyediakan guru yang baik dilatih untuk mengintegrasikan } \\
\text { pemikiran komputasi dalam aktiviti pedagogi harian mereka (Lye \& Koh, 2014 ). }\end{array}$ \\
\hline
\end{tabular}




\begin{tabular}{|l|l|}
\hline & $\begin{array}{l}\text { Sastera pendidikan Sains Komputasi mencadangkan banyak cara untuk berkembang keupayaan berfikir } \\
\text { komputasi pelajar. Sastera mengesyorkan menghubungkan. Pemikiran komputasi kepada kepentingan } \\
\text { pelajar (Resnick et al., 2009), melalui komputer permainan (Carter, 2006, Lenox, Jesse, \& Woratschek, } \\
\text { 2012) atau berasaskan multimedia tugas pembelajaran (Blank et al., 2003). }\end{array}$ \\
\hline $\begin{array}{l}\text { Repenning, Webb, \& } \\
\text { Ioannidou, 2010) }\end{array}$ & $\begin{array}{l}\text { Pendekatan berasaskan Permainan telah ditunjukkan kepada meningkatkan keseronokan pembelajaran } \\
\text { komputasi pelajar semasa membangunkan Komputasi Konsep pemikiran. }\end{array}$ \\
\hline $\begin{array}{l}\text { (Stephenson, Gal-Ezer, } \\
\text { Haberman, \& } \\
\text { Verno, 2005) }\end{array}$ & $\begin{array}{l}\text { Pengalaman pembelajaran yang bermakna dapat dicapai dengan merancang bahan kursus itu } \\
\text { menggabungkan; pendekatan penyelesaian masalah, persekitaran eksperimen dengan penekanan pada } \\
\text { pengalaman dunia sebenar yang sahih. }\end{array}$ \\
\hline $\begin{array}{l}\text { Repenning dan Ioannidou } \\
(2008)\end{array}$ & $\begin{array}{l}\text { Kepuasan pelajar dengan pengkomputeran boleh ditingkatkan dengan menyokong kemahiran di luar } \\
\text { pengaturcaraan dan ini mungkin bahkan meluaskan penyertaan selanjutnya. }\end{array}$ \\
\hline $\begin{array}{l}\text { Barr dan Stephenson } \\
{[2011]}\end{array}$ & $\begin{array}{l}\text { Berhujah bahawa pelajar hari ini akan tinggal dan bekerja di dunia yang banyak dipengaruhi dengan } \\
\text { mengira prinsip. Jika matlamat kita adalah untuk memupuk generasi dengan kemahiran CT, kita perlu } \\
\text { membiasakan pelajar dengan CT dalam pendidikan K-12 awal [Barr dan Stephenson 2011]. }\end{array}$ \\
\hline
\end{tabular}




\section{B. KAJIAN RELAVAN SELF CONFIDENCE}

\begin{tabular}{|c|c|}
\hline Bower, $M$ et al & $\begin{array}{l}\text { Kepercayaan para guru tentang keupayaan pelajar untuk meningkatkan kemampuan } \\
\text { Pemikiran Komputasi mereka. Seramai } 140 \text { orang guru menanggapi penarafan soalan } \\
\text { dengan tahap keyakinan mereka membangunkan keupayaan berfikir komputasi pelajar } \\
\text { (Sangat tidak yakin } 8 \text {, tidak yakin } 24 \text {, sedikit tidak yakin } 18 \text {, sedikit yakin } 42 \text {, yakin } 45 \text {, } \\
\text { sangat yakin } 3 \text {. } \\
\text { Sebanyak } 122 \text { guru menjawab soalan "Apa yang menghalang anda daripada merasa yakin } \\
\text { tentang membangunkan keupayaan berfikir pengkomputeran anda? "Of ini, } 31 \text { responden } \\
\text { menyatakan bahawa kekurangan pengetahuan tentang topik itu menghalang mereka daripada } \\
\text { merasa yakin dalam mengajar pemikiran komputasi, ini jawapan umumnya mencerminkan } \\
\text { kekurangan pemahaman pemikiran komputasi konsep, misalnya "mempunyai pemahaman } \\
\text { yang kuat tentang konsep yang terlibat, mengetahui jika saya bergerak ke arah yang betul. } \\
\text { "Terdapat } 21 \text { guru sahaja menjawab bahawa mereka kurang yakin kerana mereka tidak } \\
\text { menyedari apa Pemikiran komputasi adalah, sebagai contohnya "Jika saya tahu apa yang } \\
\text { sebenarnya saya tidak akan mempunyai masalah mengajarnya " }\end{array}$ \\
\hline $\begin{array}{l}\text { Bower. M dan Katrina Falkner. } 2015 . \\
\text { Computational Thinking, the Notional } \\
\text { Machine, Pre-service } \\
\text { Teachers, and Research Opportunities. } \\
\text { Proceedings of the 17th Australasian } \\
\text { Computing Education Conference } \\
\text { (ACE 2015), Sydney, } \\
\text { Australia, (hal. 37-46). }\end{array}$ & $\begin{array}{l}\text { Terdapat } 32 \text { orang guru pra-perkhidmatan yang memilih untuk bertindak balas kepada } \\
\text { soalan-soalan yang berkaitan dengan bagaimana yakin mereka merasakan untuk } \\
\text { membangunkan keupayaan pemikiran pengiraan pelajar mereka (lihat Rajah 1). Daripada } \\
\text { graf ia boleh dilihat bahawa } 18 \text { daripada } 32 \text { orang guru pra-perkhidmatan }(56 \%) \text { menyatakan } \\
\text { bahawa mereka ke tahap yang tidak yakin dan bukan yakin mengajar pemikiran pengiraan. } \\
\text { Apabila guru praperkhidmatan ditanya "apa yang menghalang anda daripada merasa yakin } \\
\text { tentang membangunkan keupayaan pemikiran pengiraan pelajar anda?" Jawapan yang } \\
\text { berkaitan dengan isu-isu pedagogi, isu-isu teknologi, isu-isu umum, keadaan dan isu-isu } \\
\text { afektif. Sembilan guru praperkhidmatan berasa tidak yakin tentang pembangunan mereka } \\
\text { pengiraan pelajar berfikir kerana isu-isu pedagogi, termasuk ketidakbiasaan dengan } \\
\text { kurikulum (5), kekurangan strategi pedagogi (3), kekurangan idea pengajaran (1), dan } \\
\text { ketidakpastian bagaimana untuk memohon pemikiran pengiraan kepada situasi dunia } \\
\text { sebenar (1). Terdapat lapan orang guru pra-perkhidmatan yang merasakan bahawa mereka } \\
\text { tidak mempunyai pengetahuan teknologi dan pengalaman untuk merasa yakin tentang }\end{array}$ \\
\hline
\end{tabular}




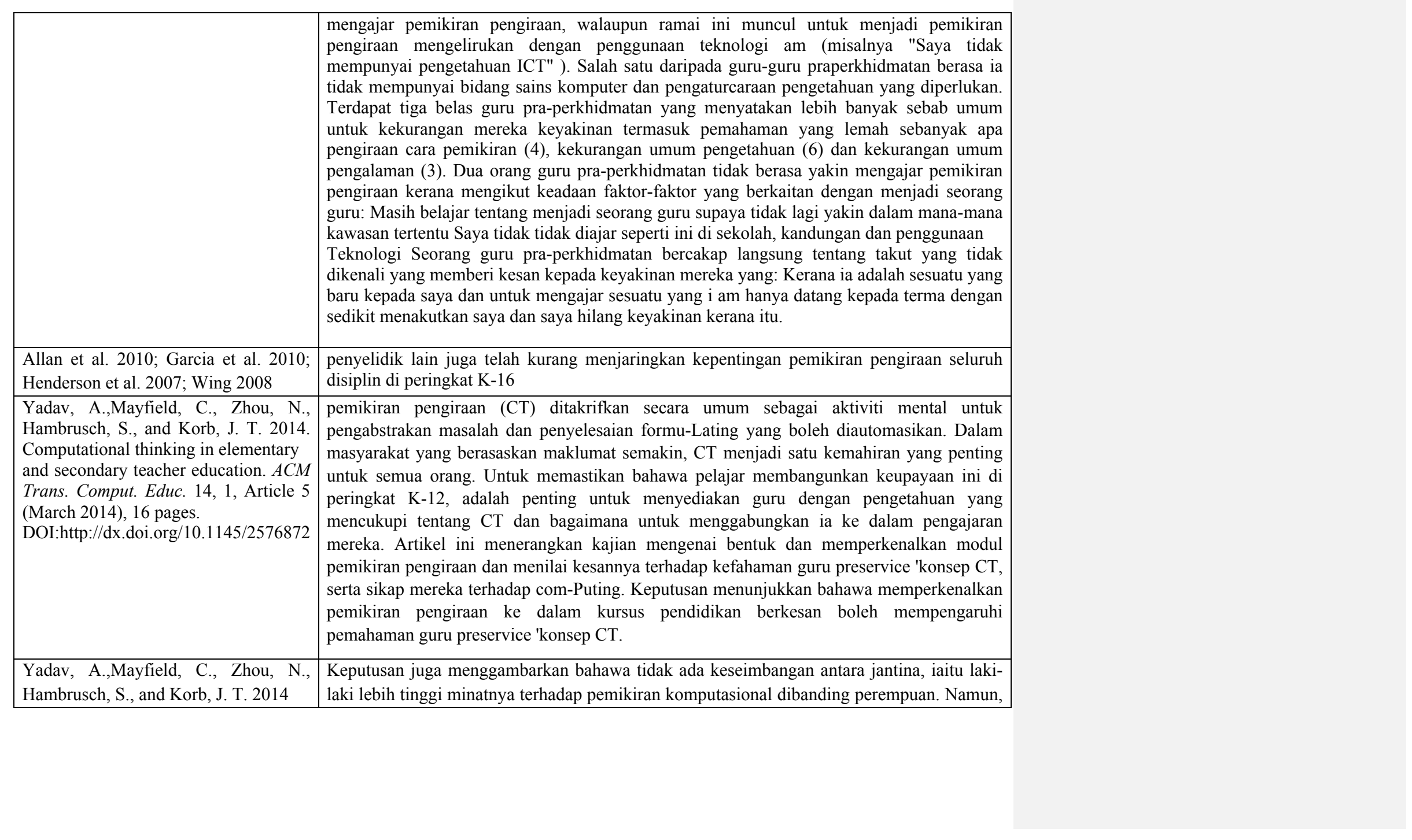




\begin{tabular}{|l|l|}
\hline & $\begin{array}{l}\text { dalam hal ini jantina bukan merupakan faktor penentu kemahiran pemikiran komputasional. } \\
\text { Dalam kajian bahawa, tidak ada interaksi yang signifikan antara keadaan dan jantina. } \\
\text { Perempuan pada masa ini kurang diberi perhatian dalam keseluruhan saluran pendidikan } \\
\text { pengkomputeran. }\end{array}$ \\
\hline [Board 2012] & $\begin{array}{l}\text { Data terkini dari Lembaga Kolej menunjukkan bahawa hanya 22\% daripada AP Penuntut } \\
\text { ujian Sains Komputer adalah wanita. }\end{array}$ \\
\hline $\begin{array}{l}\text { Yadav, A.,Mayfield, C., Zhou, N., } \\
\text { Hambrusch, S., and Korb, J. T. 2014 }\end{array}$ & $\begin{array}{l}\text { Penemuan dalam kajian kami menggalakkan, kerana mereka mencadangkan bahawa wanita } \\
\text { dan lelaki sama-sama selesa dengan pengkomputeran, dan kedua-duanya melihat } \\
\text { pengkomputeran memainkan peranan dalam karier mereka. Membina keselesaan ini dan } \\
\text { pemahaman bahawa pengkomputeran memainkan peranan penting dalam pelbagai kerjaya } \\
\text { boleh memainkan peranan penting dalam meningkatkan bilangan wanita yang mengejar } \\
\text { sains komputer. }\end{array}$ \\
\hline
\end{tabular}

\section{MEMPERKENALKAN COMPUTER THINGKING DENGAN BAHASA SEDERHANA BERKAITAN DENGAN KESEHARIAN}

\begin{tabular}{|l|l|}
\hline Yadav, A.,Mayfield, C., Zhou, N., & Kelas pertama diperkenalkan pelajar definisi pemikiran pengiraan dan lima konsep CT: \\
Hambrusch, S., and Korb, J. T. 2014. & $\begin{array}{l}\text { Pengenalpastian Masalah dan penguraian, pengambilan, pemikiran logik, algoritma, dan } \\
\text { debugging. Memandangkan guru preservice tidak mempunyai sebelum latar belakang sains } \\
\text { komputer, kita digambarkan konsep-konsep ini dengan contoh-contoh konkrit dari kehidupan }\end{array}$ \\
& $\begin{array}{l}\text { sehari-hari dan yang berkaitan istilah dengan pengalaman peribadi guru preservice '. kelas } \\
\text { bermula dengan pengajar meminta sepasang pelajar untuk membangunkan arah pemanduan } \\
\text { dari titik A ke titik B. pengajar ini telah membawa pelajar dalam perbincangan bagaimana } \\
\text { mereka datang dengan arahan (mengenal mereka, dilakarkan peta, mengambil yang terbaik }\end{array}$ \\
laluan, bertanya kepada seorang rakan, dan lain-lain) dan bagaimana menyeluruh arahan \\
mereka adalah (beberapa langkah, terperinci turn-oleh-belok) menggunakan soalan clicker.
\end{tabular}

\begin{tabular}{|l|l|l}
\hline Aman Yadav, Sarah Gretter, Jon & Adalah penting untuk diperhatikan bahawa compu- Pemikiran tenting tidak semata-mata \\
\hline
\end{tabular} 


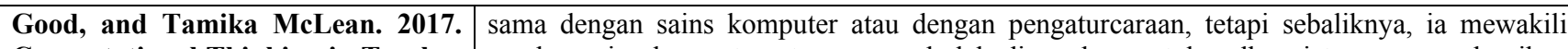
Computational Thinking in Teacher amalan sains komputer utama yang boleh digunakan untuk pelbagai tugas menyelesaikan Education. DOI 10.1007/978-3-319- masalah.

52691-1_13.

(CSTA \& ISTE,

$\underline{2011}$; Selby, 2015 ).

Bukan sahaja boleh berfikir berfikir- Dalam menyediakan pelajar untuk pekerjaan pengkomputeran, ia juga menyediakan mereka untuk berfikir di luar kotak dan gunakan kemahiran menyelesaikan masalah dengan atau tanpa sokongan komputer bidang yang berbeza dalam kehidupan peribadi, akademik, dan profesional mereka.

\section{KOMPONEN COMPUTER THINGKING}

\begin{tabular}{|l|l|}
\hline Wing (2006) & $\begin{array}{l}\text { menyatakan bahawa kemahiran pemikiran komputasional asas adalah Leraian } \\
\text { (Decomposition), Pengecaman corak (Pattern Recognition), Penskalaan } \\
\text { (Abstraction), dan Pengitlakan (Algorithms). }\end{array}$ \\
\hline Barr and Stephenson (2011) & $\begin{array}{l}\text { proposed nine core computational thinking concepts and abilities to integrate CT } \\
\text { concepts in K-12 classrooms across core content areas. These core computational } \\
\text { thinking ideas include data collection, data analysis, data representation, problem } \\
\text { decomposition, abstraction, algorithms and procedures, automation, parallelization, } \\
\text { and simulation. }\end{array}$ \\
\hline $\begin{array}{l}\text { Tengok JuMPUTATIONAL THINKING } \\
\text { IN TEACHER EDUCATION }\end{array}$ & $\begin{array}{l}\text { These computational thinking concepts can be implemented in K-12 classrooms } \\
\text { through digital storytelling, data collection and analysis, and scientific investigations } \\
\text { (Lee, Martin \& Apone, 2014), creating games (Howland \& Good, 2015; Lee et al., } \\
\text { 2014; Nickerson, Brand, \& Repenning, 2015), educational robotics (Atmatzidou \& } \\
\text { Demetriadis, 2014), physics (Dwyer, Boe, Hill, Franklin, \& Harlow, 2013), visual } \\
\text { programming languages like Scratch or other interactive media (Brennan \& Resnick, } \\
\text { 2012; Calao, Moreno-Leon, Correa, \& Robles, 2015), and even through maker } \\
\text { movements (Rode et al., 2015). }\end{array}$ \\
\hline
\end{tabular}




\begin{tabular}{|c|c|}
\hline $\begin{array}{l}\text { Computer Science Teachers } \\
\text { Association (CSTA) and the } \\
\text { International Society for Technology } \\
\text { in Education (ISTE) }\end{array}$ & $\begin{array}{l}\text { Mereka menggunakan satu set konsep, seperti abstraksi, rekursi, dan lelaran, untuk } \\
\text { memproses dan menganalisis data, dan untuk membuat artifak sebenar dan maya. }\end{array}$ \\
\hline Aho $(2012)$ & $\begin{array}{l}\text { Pemikiran komputasional sebagai proses pemikiran yang melibatkan perumusan } \\
\text { masalah sehingga pelajar boleh menyelesaikan masalah melalui langkah-langkah } \\
\text { pengiraan dan algoritma. Manakala Selby dan Woollard (2013) mengartikan } \\
\text { pemikiran komputasional sebagai proses kognitif atau mental, manusia, bukan mesin, } \\
\text { penyelesaian masalah dalam erti kata yang luas, dan melibatkan kebolehan seperti: } \\
\text { Abstraksi (Penskalaan), iaitu menyembunyikan kerumitan realiti yang wujud untuk } \\
\text { mewakili aspek pentingnya sahaja; Penguraian, membahagikan tugas atau masalah ke } \\
\text { dalam bahagian mudah supaya lebih mudah menyelesaikan masalah yang rumit; } \\
\text { Algoritma, menentukan tugas sebagai satu set langkah demi langkah dengan } \\
\text { memiliki arahan yang mudah; Penilaian, menilai kelebihan dan batasan penyelesaian; } \\
\text { serta Pengumuman, iaitu keadaan khusus ke lebih umum. }\end{array}$ \\
\hline Csizmadia, A. et al. (2015) & $\begin{array}{l}\text { Pemikiran Komputasional merupakan proses penyelesaian masalah yang memerlukan } \\
\text { usaha memecahkan sesuatu masalah kepada komponen yang lebih kecil } \\
\text { (Decompose), cuba mengekstrak idea ataupun maklumat yang penting dan relevan } \\
\text { (Abstraction), mengenali corak (Pattern) yang membolehkan perancangan } \\
\text { penyelesaian yang tepat bagi mengelakkan ulangan dan tindakan yang kurang releven } \\
\text { supaya meningkatkan keberkesanan proses penyelesaian masalah tersebut. Individu } \\
\text { perlu menggunakan pemikiran logikal (Logical Reasoning) bagi mengenalpasti } \\
\text { maklumat yang penting dan mengaturkan langkah penyelesaian mengikut turutan } \\
\text { yang logikal (Algorithm), menilai pemilihan dan keputusan yang telah dilakukan bagi } \\
\text { menguji kesahihan dan keboleh laksanaan prosedur tersebut (Evaluation). }\end{array}$ \\
\hline $\begin{array}{l}\text { (Shaundra B, Daily, Alison E } \\
\text { Leonard, Sophie Jörg, Sabarish } \\
\text { Babu, Kara Gundersen, Dhaval } \\
\text { Parmar, 2015). }\end{array}$ & $\begin{array}{l}\text { The basic character of co mputational thin king is abstraction and automation } \\
\text { Shaundra B, Daily, Alison E Leonard, Sophie Jörg, Sabarish Babu, Kara Gundersen, } \\
\text { Dhaval Parmar.(2015) "Embodying Computational Thinking: Initial Design of an } \\
\text { Emerging Technological Learning Tool", Technology, Knowledge and Learning, } \\
\text { 20(1), pp.79-84. }\end{array}$ \\
\hline
\end{tabular}




\section{E. KEPENTINGAN GURU MENGGUNAKAN COMPUTER THINGKING}

\begin{tabular}{|l|l|}
\hline Barr dan Stephenson ( 2011) & $\begin{array}{l}\text { Highlighted that a systematic change regarding CT implementation in school couldnot be } \\
\text { accomplished without educational policies that include teacher preparation to help educators } \\
\text { understand and implement CT in their teaching. Even though most of the computational } \\
\text { thinking initiatives we describe in this chapter underline the necessity to train teachers in all } \\
\text { subject areas to embed CT, little has been done to examine the instructional, curricular, and } \\
\text { pedagogical implications for teacher preparation, particularly for preservice teachers (Lye \& } \\
\text { Koh, 2014). }\end{array}$ \\
\hline (Prieto-Rodriguez \& Berretta, 2014) ). & $\begin{array}{l}\text { Terdapat keperluan yang semakin meningkat untuk guru-guru bersedia untuk } \\
\text { mengintegrasikan CT ke dalam mereka amalan kelas. }\end{array}$ \\
\hline
\end{tabular}

